\title{
Experimental testing and simulation of bolted beam-column connections having thick extended endplates and multiple bolts per row
}

\author{
Gary S. Prinz ${ }^{\mathrm{a}, *}$, Alain Nussbaumer ${ }^{\mathrm{b}}$, Luis Borges ${ }^{\mathrm{c}}$, Shyam Khadka ${ }^{\mathrm{d}}$ \\ ${ }^{a}$ Dept. of Civil Engineering, University of Arkansas, Fayetteville, AR, USA \\ ${ }^{\mathrm{b}}$ Steel Structures Laboratory (ICOM), École Polytechnique Fédérale de Lausanne (EPFL), Switzerland \\ ' ISISE, Department of Civil Engineering, University of Coimbra - Pollo II, Portugal \\ ${ }^{\mathrm{d}}$ Department of Civil \&' Geomatics Engineering, Kathmandu University, Nepal
}

\section{A R T I C L E I N F O}

\section{Article history:}

Received 22 February 2013

Revised 28 September 2013

Accepted 31 October 2013

\section{Keywords:}

Experimental testing

Bolted connections

Extended end-plates

Component methods

Nonlinear finite element analysis

\begin{abstract}
A B S T R A C T
Retrofit of existing steel buildings often requires strengthening of the connection regions. One common connection, the bolted beam-column connection, is often strengthened in design using stiffened extended endplates, or with continuity plates welded between the column flanges. In a retrofit scenario, adding stiffeners to the endplate is difficult due to the concrete slab and metal deck, and excessive field welding of continuity plates may be uneconomical. Simplifying retrofit efforts, and for economy, connection strength may be improved by simply adding more bolts to the connection. Current code methods, broadly generalized to all connection configurations, are currently based on component experiments having only one bolt on either side of the column web. This study experimentally investigates strengthening of bolted beam-column connections, having no column web stiffeners, using more than one bolt on either side of the column web. Six full-scale bolted beam-column connections are tested, representing exterior beamcolumn connections (beams attached to only one column flange). Connections with both extended and flush endplates are considered. Two column sections (HE300A and HE300B) are tested along with HE300B beams creating both equal-column-beam, and weak-column strong-beam scenarios. Analytical simulations provide insight into local connection demands, and experimental results are compared with current code methods. The experiments indicate that closer inner-bolt spacing relative to the column web increases connection moment capacity but decreases rotation capacity (connection ductility) due to increased bolt prying forces from column flange distortions. The outer bolt of multiple-bolt-per-row configurations contributes very little to the connection resistance when column web stiffeners are not considered. With the exception of specimen T-3B which failed through bolt-thread shear after $0.02 \mathrm{rad}$, all connections with multiple bolts per row still achieved rotations greater than $0.06 \mathrm{rad}$. The Eurocode 3 component method and adapted Eurocode 3 procedures conservatively predicted the connection strength of each test specimen, including weak-column strong-beam assemblies, and accurately identified the initial connection limit states.
\end{abstract}

(c) 2013 Elsevier Ltd. All rights reserved.

\section{Introduction}

Understanding the strength and rigidity of connection regions is necessary for the efficient design of steel building systems. One common steel building connection, the bolted beam-column connection, is often assumed as either fully pinned or fully rigid; however in reality, the rigidity of such connections is somewhere inbetween (a semi-rigid connection). Required strength of beams and columns in a building system depend directly on the considerations made for the connection rigidity [1]. Moreover, in retrofit scenarios where strengthening of connections is needed, accurate

\footnotetext{
* Corresponding author. Tel.: +1 (479) 5752494.

E-mail address: prinz@uark.edu (G.S. Prinz).
}

understanding of existing and improved connection rigidity is required. To estimate the true behavior of bolted beam-column connections, the Eurocode has adopted the component method [2], which considers individual connection components (bolts, flanges, webs, endplates, etc.) and their interactions.

The component method presented in the Eurocode 3, EN1993 part 1.8 (hereafter referred to as EC3-1.8) is based on research published in the early 1980 s by Zoetemeijer [3,4] and can be summarized in five general steps: (1) identification of the load-path through the connection; (2) determination of individual component strength within the load path (for example, the compressive strength of the column web, tensile strength of the beam flange, etc.); (3) determination of individual component stiffness in the load path; (4) assembly of the individual components in series and or parallel (depending on their arrangement); and (5) determi- 
nation of the "weakest link" in the load path based on individual strength and deformation capacity. Fig. 1 shows a typical beamcolumn connection and the component method representation.

Many analytical and experimental studies have investigated bolted beam column connections [5-12] along with the predictive capabilities of the EC3-1.8 component method. One such study by Abidelah et al. [13] investigated the strengthening of bolted beamcolumn connections by comparing configurations with and without stiffeners in the extended endplate portion. In [13], results showed that additional endplate stiffeners increase moment capacity but decrease connection ductility. The EC3-1.8 component method accurately predicted the connection failure modes in the strengthened connections; however, connection strength was consistently under-predicted. All connections in [13] had two bolts per row (one bolt on either side of the column web) and column web stiffeners were not used.

Although connection strength may be increased using endplate stiffeners, in a retrofit scenario adding endplate stiffeners is difficult when a concrete slab or metal deck is present. Adding another bolt on either side of the column web may result in similar connection strength gain while simplifying retrofit application. Additionally, it is often more economical to use multiple bolts per row when wide H-sections are used [14]; however, current code methods, broadly generalized to all connection configurations, are currently based on T-stub experiments $[3,4]$ having only one bolt on either side of the column or beam web. While a few analytical studies have investigated connections having four bolts-per-row $[14,15]$, limited experimental data exists in the literature comparing the performance of the EC3-1.8 component method with connection configurations having multiple bolts per row.

This study experimentally investigates the interactive behavior of bolted beam-column connections having thick extended endplates and multiple bolts per row (without column web stiffeners). Weak column strong beam situations are considered. Six beamcolumn connections having various bolt configurations and section dimensions are tested. Detailed numerical models are also created to determine detailed stress and strain distributions within the connection regions, and to investigate techniques for simulating semi-rigid bolted connections having multiple bolts per row. Both the experimental and numerical tests are compared with the current EC3-1.8 component method. The study begins with an overview of the experimental program, followed by numerical modeling methods and result comparisons. Conclusions on the performance of bolted beam-column connections are provided.

\section{Experimental program}

An experimental program was developed to determine the static monotonic behavior of bolted beam-column connections having multiple bolt configurations, with the main objectives being: (1) determine the influence of bolt grouping (multiple bolts per row) and thick endplates on connection response; (2) determine the different connection failure modes; and (3) compare experimental performance with code methods. The following sections discuss the experimental program in detail and present results based on the objectives outlined above.

\subsection{Test specimens}

The experimental specimens consist of a column element and a beam element which is fully welded to an endplate. The beam and column elements are connected using multiple GR10.9 zinc coated M20 bolts with zinc coated GR10.9 HV nuts and standard GR4.6 washers. Note that standard GR4.6 washers were used in place of high-strength GR10.9 washers due to a specimen delivery error; however, additional testing is conducted herein to ensure negligible washer influence on connection response (see later section on T-stub testing). All bolts are pre-tightened with $480 \mathrm{~N}-\mathrm{m}$ of torque as per [16].

A total of six beam-column connections are considered, representing three different bolt configurations (both extended and non-extended configurations) and two column profiles. The various specimen configurations are chosen to: (1) compare the response of bolt configurations having multiple bolts per row with typical configurations having two bolts per row (using bolt spacing comparable to typical design); (2) determine bolt grouping influence in weak-column strong-beam and equal-column-beam scenarios; and (3) determine the influence of extended endplates on configurations using multiple bolts per row. All beam and column elements are fabricated from S235 steel while the endplates are fabricated from S355 steel following typical practice. Fig. 2 shows the specimen geometry including endplate and bolt group details; Table 1 shows the experimental test matrix; and Table 2 presents the specimen material properties. Shown in Table 1 , the column profile tested in group $\mathrm{A}$ (specimens $1 \mathrm{~A}, 2 \mathrm{~A}$, and $3 \mathrm{~A}$ ) is an $\mathrm{HE}$ $300 \mathrm{~A}$ section having a web thickness of $8.5 \mathrm{~mm}$ and a flange thickness of $14 \mathrm{~mm}$; the column profile tested in group B is an HE 300B section having a larger web and flange thickness $(11 \mathrm{~mm}$ and $19 \mathrm{~mm}$ respectively). The beam (HE 300B) is the same for all

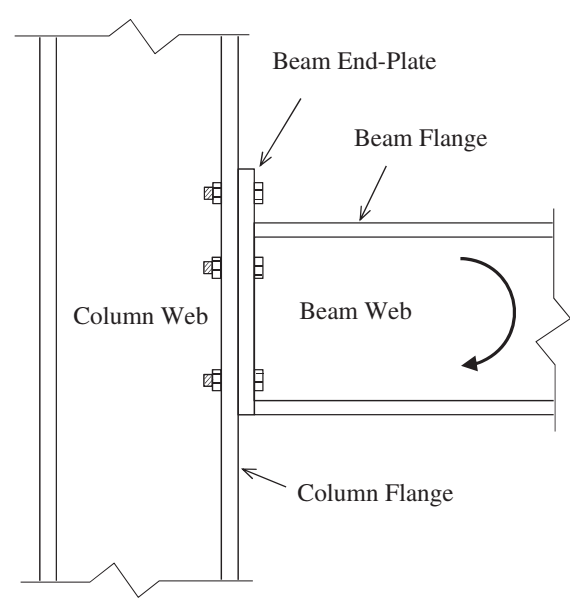

(a)

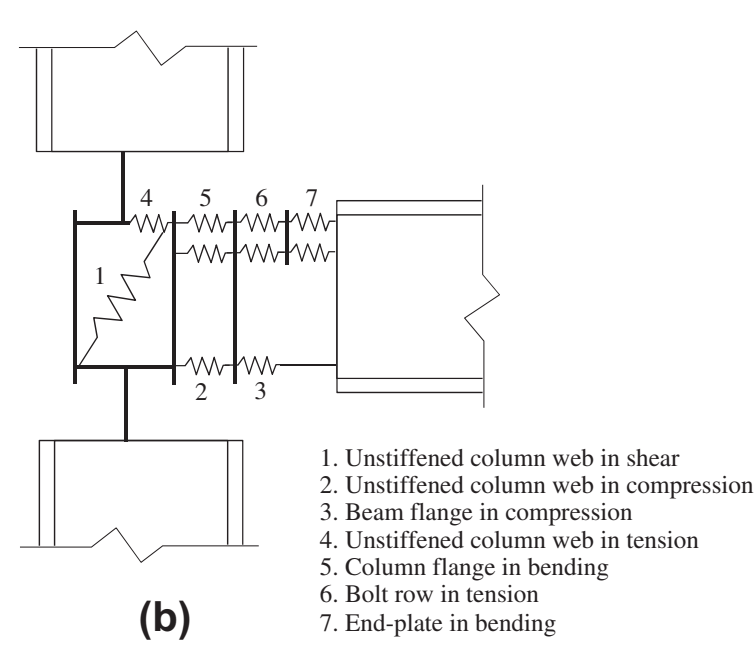

(b)
6. Bolt row in tension
7. End-plate in bendin
. Unstiffened column web in compression

3. Beam flange in compression

4. Unstiffened column web in tension

Fig. 1. (a) Typical beam-column bolted connection and (b) component method representation. 

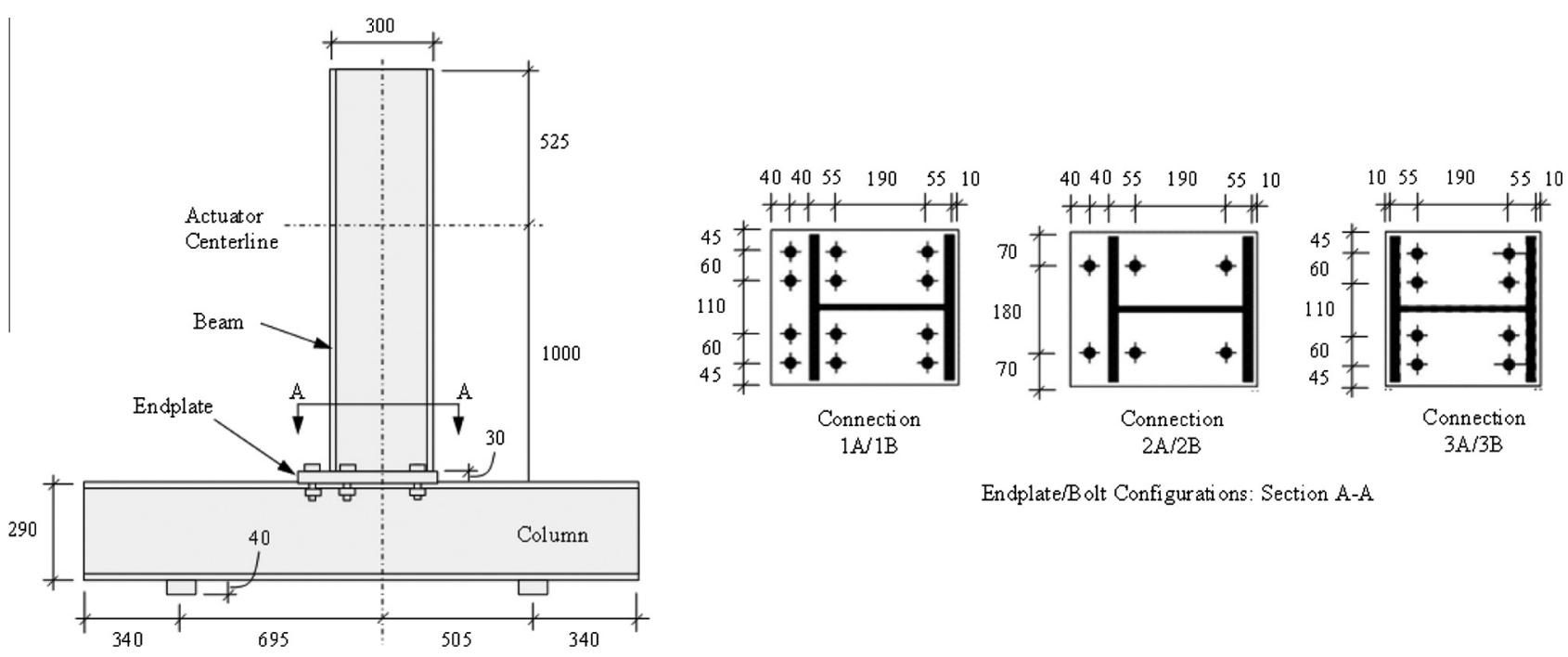

Endplate/B olt Configurations: Section A-A

Fig. 2. Test specimen geometry.

Table 1

Test matrix.

\begin{tabular}{|c|c|c|c|c|}
\hline Specimen & Column element & Beam element & Number of bolts & Bolt/endplate configuration \\
\hline $1 \mathrm{~A}$ & HE 300A & HE 300B & 12 & 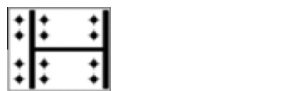 \\
\hline $2 \mathrm{~A}$ & HE 300A & HE 300B & 6 & $+1+$ \\
\hline $3 \mathrm{~A}$ & HE 300A & HE 300B & 8 & \begin{tabular}{ll|}
+ & +1 \\
& +
\end{tabular} \\
\hline 1B & HE 300B & HE 300B & 12 & $: \mid$\begin{tabular}{ll|}
$*$ & +1 \\
$+\mid+$ & +
\end{tabular} \\
\hline 2B & HE 300B & HE 300B & 6 & $\begin{array}{|ll|}+ & + \\
& + \\
& +\end{array}$ \\
\hline 3B & HE 300B & HE 300B & 8 & $\begin{array}{ll}+ & +1 \\
1 & + \\
& +1\end{array}$ \\
\hline
\end{tabular}

Table 2

Beam, column, and endplate material characteristics.

\begin{tabular}{|c|c|c|c|c|c|c|c|c|c|c|c|c|c|c|c|}
\hline \multirow{2}{*}{$\begin{array}{l}\text { Material } \\
\text { grade }\end{array}$} & \multirow[t]{2}{*}{ Element } & \multirow{2}{*}{$\begin{array}{l}\text { Yield stress } \\
(\mathrm{MPa})\end{array}$} & \multirow{2}{*}{$\begin{array}{l}\text { Ultimate stress } \\
(\mathrm{MPa})\end{array}$} & \multirow{2}{*}{$\begin{array}{l}\text { Fracture } \\
\text { strain }\left(\varepsilon_{f}\right)\end{array}$} & \multicolumn{11}{|c|}{ Chemical composition } \\
\hline & & & & & $\% \mathrm{C}$ & \%Mn & $\% \mathrm{P}$ & $\% S$ & $\% \mathrm{Si}$ & $\% \mathrm{~N}$ & $\% \mathrm{Cu}$ & $\% \mathrm{Ni}$ & $\% \mathrm{Cr}$ & $\% \mathrm{~V}$ & \%Mo \\
\hline S235 JR+M & HE 300A & 353 & 433 & 0.320 & 0.060 & 0.670 & 0.033 & 0.026 & 0.220 & 0.009 & 0.390 & 0.160 & 0.160 & 0.007 & 0.040 \\
\hline S235 JR+M & HE 300B & 346 & 433 & 0.320 & 0.070 & 0.660 & 0.030 & 0.026 & 0.180 & 0.009 & 0.360 & 0.190 & 0.200 & 0.006 & 0.030 \\
\hline $\mathrm{S} 355 \mathrm{~J} 2+\mathrm{N}$ & Endplate & 366 & 538 & 0.279 & 0.190 & 1.470 & 0.015 & 0.009 & 0.220 & 0.006 & 0.060 & 0.030 & 0.030 & 0.002 & 0.005 \\
\hline
\end{tabular}

specimens, creating a weak-column strong-beam scenario for specimens $1 \mathrm{~A}, 2 \mathrm{~A}$, and $3 \mathrm{~A}$. The endplate thickness of each specimen is $30 \mathrm{~mm}$.

\subsection{Test configuration, instrumentation, and loading}

The experimental setup shown in Fig. 3 is designed to investigate the response of bolted beam-column connections during beam overloading. In Fig. 3, the column section rests horizontally on two supports, preventing column-flange contact with the ground and allowing column rotations within the connection re- gion. The beam extends vertically from the column, and is connected to a horizontal actuator where the displacement controlled loading is applied. To prevent sliding of the specimen during loading, four pre-tensioned rods (two on either side of the column web) clamp the column flange to the testing floor.

Various measuring devices attached to the specimen are used to record local and global connection behavior. Twelve unidirectional strain gauges and four linear variable differential transducers (LVDTs) are attached to each specimen to record local member strains and global connection displacements. Two strain gauges located on each beam flange near the connection (four gauges in to- 


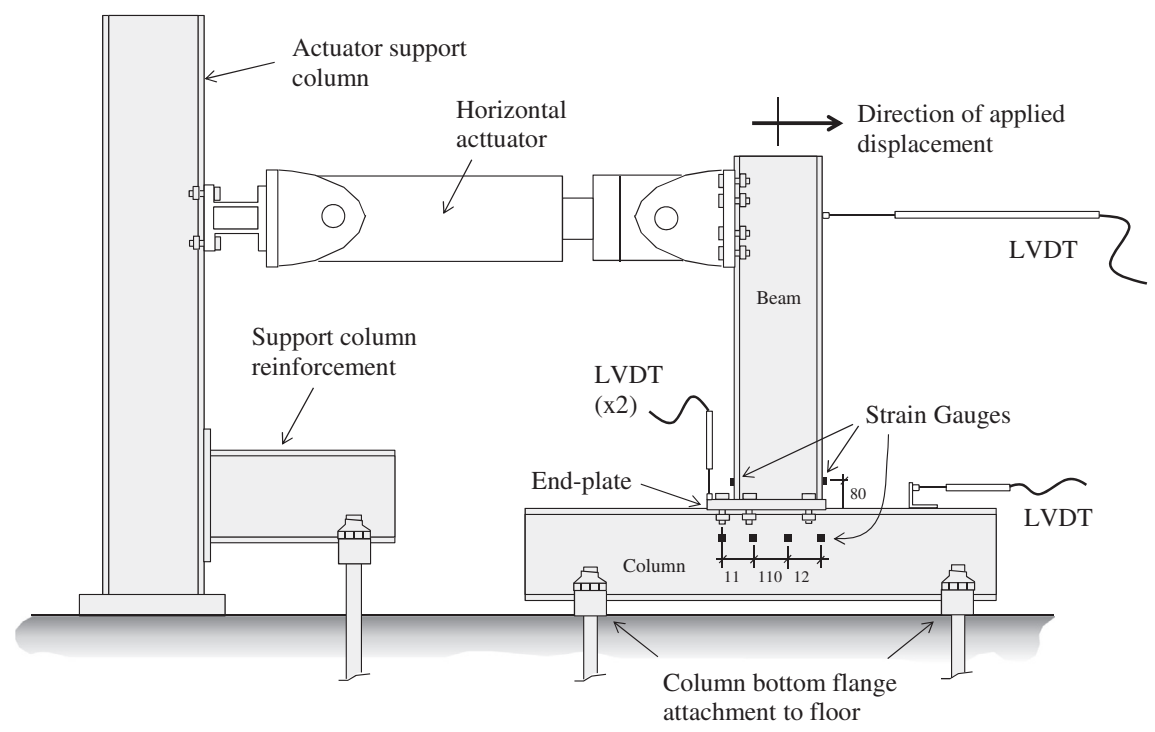

Fig. 3. Experimental setup with instrumentation locations.

tal) allow for determination of beam moment demands; four strain gauges located on each side of the column web near the connection (eight gauges in total) measure local column web demands; two LVDTs located on the extended portion of end-plate (on the column flange for the flush endplate connections) determine plate uplift; one LVDT attached to the column element records any slip between the column and floor; and a single horizontal LVDT attached to the beam at the centerline of the horizontal actuator records beam displacements. Fig. 3 shows the applied instrumentation.

The connection loading protocol consists of two phases: (1) elastic load and unload to engage specimen supports and fasteners, and (2) static monotonic loading up to connection failure. In the first loading phase, $3 \mathrm{~mm}$ of displacement is applied and then removed at a strain rate of $0.1 \mathrm{~mm} / \mathrm{s}$. Following, monotonic loading up to ultimate failure is applied at the same strain rate of $0.1 \mathrm{~mm} / \mathrm{s}$ for the remainder of the test. Ultimate failure is defined in this study as a $20 \%$ reduction in connection moment capacity.

\section{Experimental results}

\subsection{Observations and governing failure modes}

Two failure limit levels are considered, (1) a classical failure limit based on initial component yielding (used to compare code methods and experimental results), and (2) an ultimate failure limit defined as a $20 \%$ reduction in connection moment capacity. In each test, column flange capacity was observed to be the initial limiting component, with large deformations clearly visible within the connection tensile zone (see Fig. 4(b)). Residual flange deformations after testing indicated significant yielding. Following large flange deformations, bolt failure occurred in each test, reducing connection capacity to below $80 \%$ of ultimate.

For beam-column connections having extended endplates, complete bolt fracture always occurred in the extended section on the bolt group closest to the column web; for beam column connections with flush endplates, bolt failure occurred in the tensile zone on the bolt group closest to the column web. Higher demands on the bolts nearest the column web are attributed to relative deformations between the endplate and column flange created from the increased flange stiffness near the web (see Fig. 4(a)). As column flange deformations increase, flange behavior transitions from flexural to membrane action, increasing bolt prying demands making bolt failure unavoidable. Fig. 5 shows this flexural-to-membrane flange transition, which occurs near 0.04 rad of rotation for the geometries tested in this study.

Excepting specimen T3B (having a flush endplate), tensile fracture of the complete bolt cross-section occurred in each test after the 0.04 rad flexural-to-membrane flange transition limit. In specimen T3B, bolt-thread shear failure occurred at 0.027 rad of

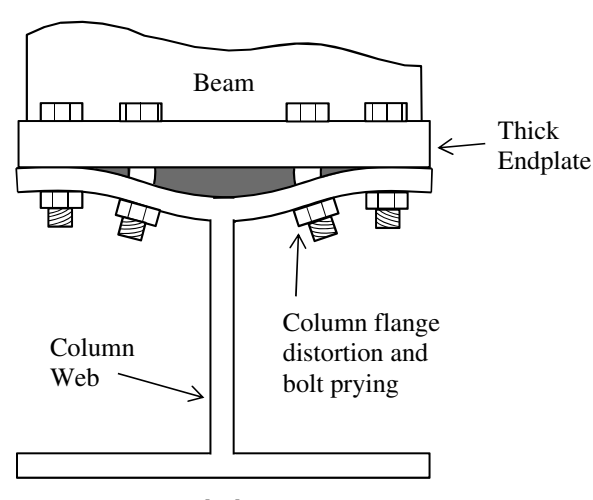

(a)

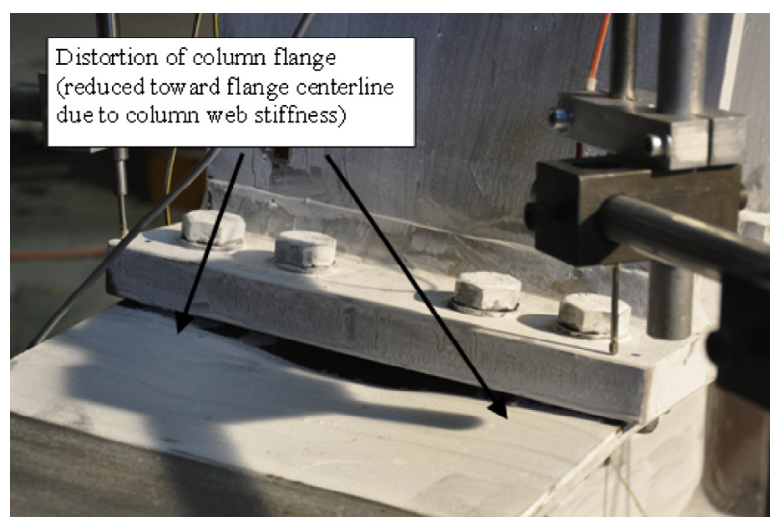

(b)

Fig. 4. Observed column flange distortion and bolt prying for specimen T1A. 


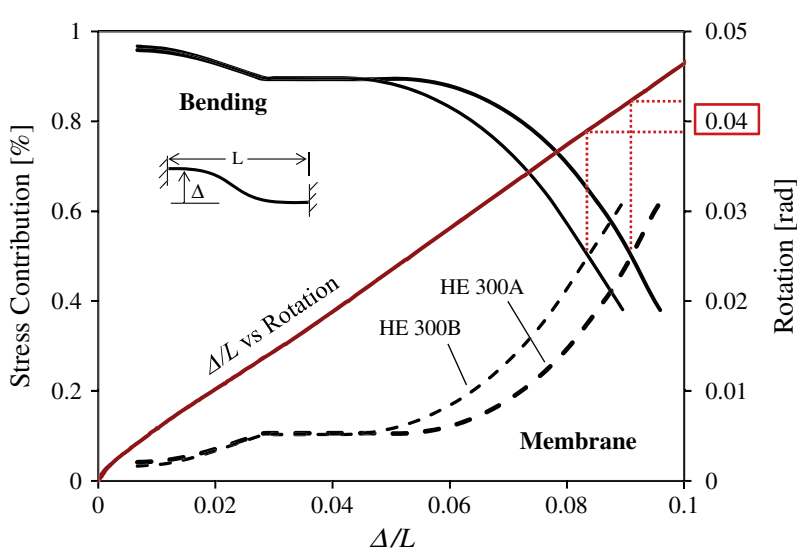

Fig. 5. Flange flexural-to-membrane behavior transition and corresponding connection rotation.

rotation. Fig. 6 shows the fractured bolts for specimens T1A through T3A and bolt-thread shear for specimen T3B. Fig. 7 shows the deformed shape of the T1B beam-column assembly corresponding to the peak moment (just after bolt failure).

Following bolt fracture, permanent deformation was observed in the GR4.6 washers (bending and compressive yielding); however, the performance of the GR4.6 washers compared to standard high-strength washers was identical, as will be explained with Tstub tests in a later section.

\subsection{Moment-rotation behavior}

The use of four bolts per row and extended endplates increases connection moment capacity but may reduce rotation capacity. Fig. 8 shows the moment rotation behavior for all six beam-column connection configurations. In this study, the connection moment is determined using a lever-arm between the column flange-to-endplate contact zone and the applied horizontal load. This method for calculating the connection moment is justified as no column web buckling was observed. As could be expected, extended endplate configurations having two bolts on either side of the beam web (four bolts per row, specimens T1A and T1B) achieved higher moment capacity than the corresponding specimens having one bolt on either side of the column web (two bolts per row, specimens T2A and T2B) (on average 29.5\% higher capacity).

Weak-column strong-beam extended endplate specimens with only two bolts per row achieved 52\% more rotation than corresponding specimens with four bolts per row (compare T1A and $\mathrm{T} 2 \mathrm{~A}$ ). This increase in rotation capacity is likely due to the flexible column flange and increased distance between the bolt and column-web, resulting in decreased rotational stiffness and decreased prying between the endplate and column flange at comparable rotation values (see again Fig. 4). A similar reduction in rotation capacity was not observed between the equal column-beam specimens having thicker column flanges (compare specimens T1B and

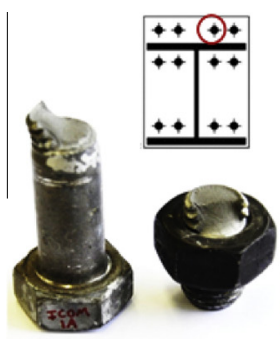

Specimen 1A

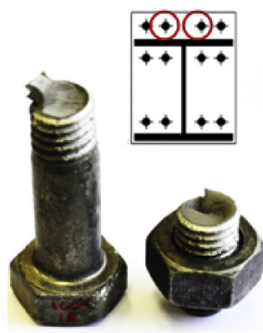

Specimen 1B

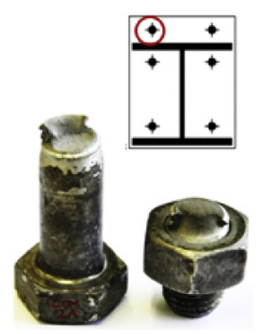

Specimen 2A

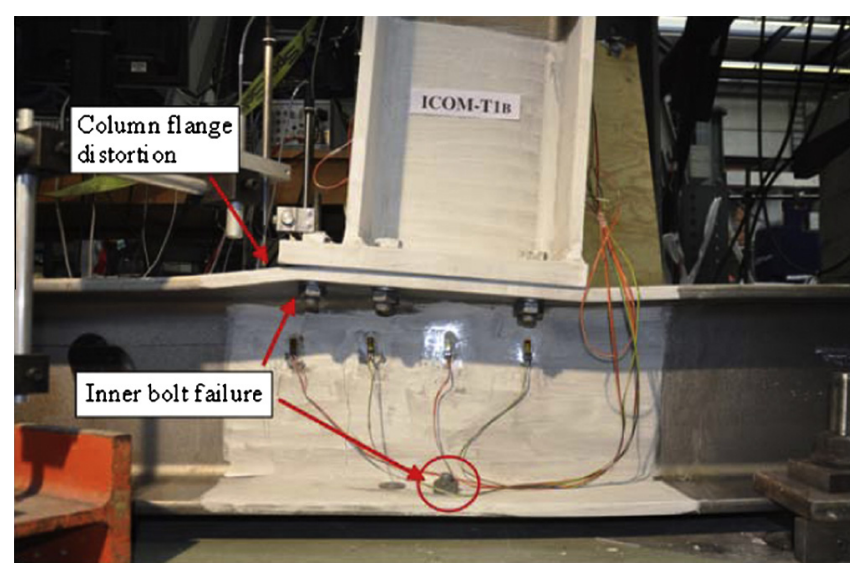

Fig. 7. Connection rotation at peak applied moment for specimen T1B.

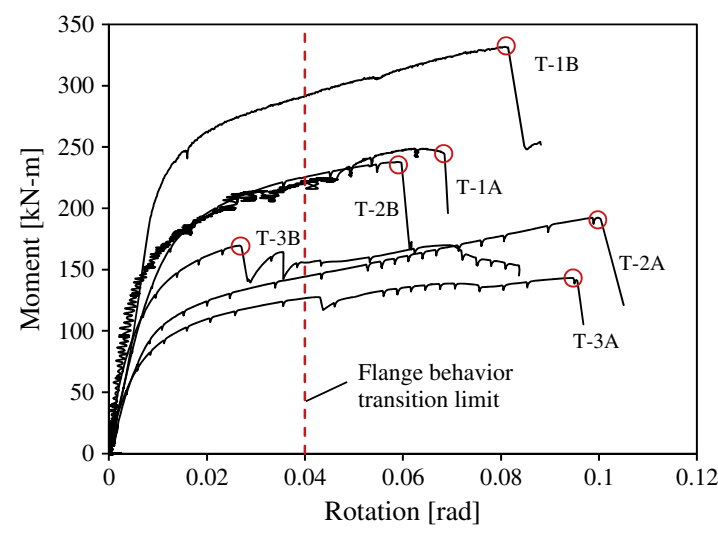

Fig. 8. Moment-rotation behavior for all six test specimens.

T2B). Table 3 shows the strength, stiffness, and ultimate rotation values for each test. Note in Table 3 that the rotational stiffness of specimen T1A, having four bolts per row, is more than twice that of specimen T2A having two bolts per row.

All specimens having extended endplates achieved higher moment resistance than the flush endplate connections. Comparing specimen T2A (having an extended endplate and two bolts per row) with specimen T3A (having a flush endplate and four bolts per row) indicates $34 \%$ higher capacity with the extended endplate connection (see Fig. 8).

\subsection{Effect of column section and bolt group on web strains}

Fig. 9 shows the distribution of column-web strains for each connection configuration. The column-web strains in Fig. 9

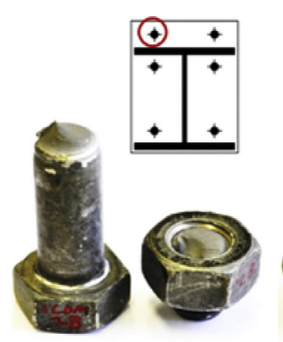

Specimen 2B

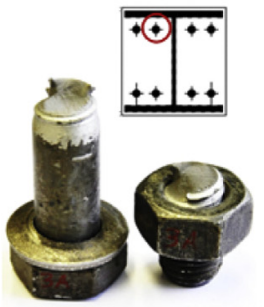

Specimen 3A

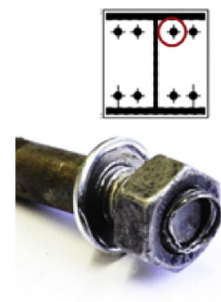

Specimen 3B

Fig. 6. Beam-column connection bolt failures. 
Table 3

Connection strength, stiffness, and rotation values.

\begin{tabular}{|c|c|c|c|c|}
\hline Specimen & No. of bolts & Ultimate strength ( $\mathrm{kN} \mathrm{m}$ ) & Rotational stiffness ( $\mathrm{kN} \mathrm{m}$ ) & Peak rotation (rad) \\
\hline T1A & 12 & 248.6 & 26,341 & 0.069 \\
\hline $\mathrm{T} 2 \mathrm{~A}$ & 6 & 192.4 & 12,346 & 0.105 \\
\hline T3A & 8 & 143.2 & 14,268 & 0.097 \\
\hline T1B & 12 & 331.7 & 22,313 & 0.081 \\
\hline $\mathrm{T} 2 \mathrm{~B}$ & 6 & 237.8 & 17,577 & 0.062 \\
\hline T3B & 8 & 169.9 & 27,277 & $0.027^{\mathrm{a}}$ \\
\hline
\end{tabular}

a Reduction to $80 \%$ of ultimate capacity after $0.027 \mathrm{rad}$, specimen regained strength and achieved $0.084 \mathrm{rad}$.

represent only axial web compression and tension; strain contributions from web bending have been removed through strain gauge averaging. As could be expected, extended endplate connections having four bolts per row experienced higher column web strains than the corresponding connections having two bolts per row (300\% higher for column sections HE300A, and 66\% higher for column sections HE300B). This increase is likely due to the closer spacing of the bolts, relative to the column web, created from the two bolts on either side of column web. Additionally, with the exception of specimen T3B which experienced early bolt-thread shear failure, specimens having HE300B column sections (specimens in Group B, see Fig. 9) experienced higher column web strains. This is likely due to increased resistance of the column flange transferring higher connection demands to the web. The strain required to initiate web material yielding was exceeded in each test. Interestingly, the neutral axis remained relatively constant between connection configurations.
Measured bending strains in the column web were low compared to the measured axial strains. Bending strain distributions in the column web under the compression edge of each beam endplate were less than $6.5 \%$ of the measured axial strains, indicating limited buckling and out-of-plain distortion in the column web.

\section{T-stub testing}

To explore the influence of washer strength on bolt demands and to further explore bolt participation in configurations having multiple bolts per row, three T-stub connections are also tested. The first T-stub connection (specimen TS1) explores the influence of washer strength on bolt prying and bolt pre-stress using GR 10.9 HV bolts and both GR 4.6 and GR 10.9 washers. The next two T-stub connections (specimens TS2 and TS3) consider four bolt-per-row and two bolt-per-row configurations, having the same spacing between the T-stub web and inner bolt. Fig. 10(a)

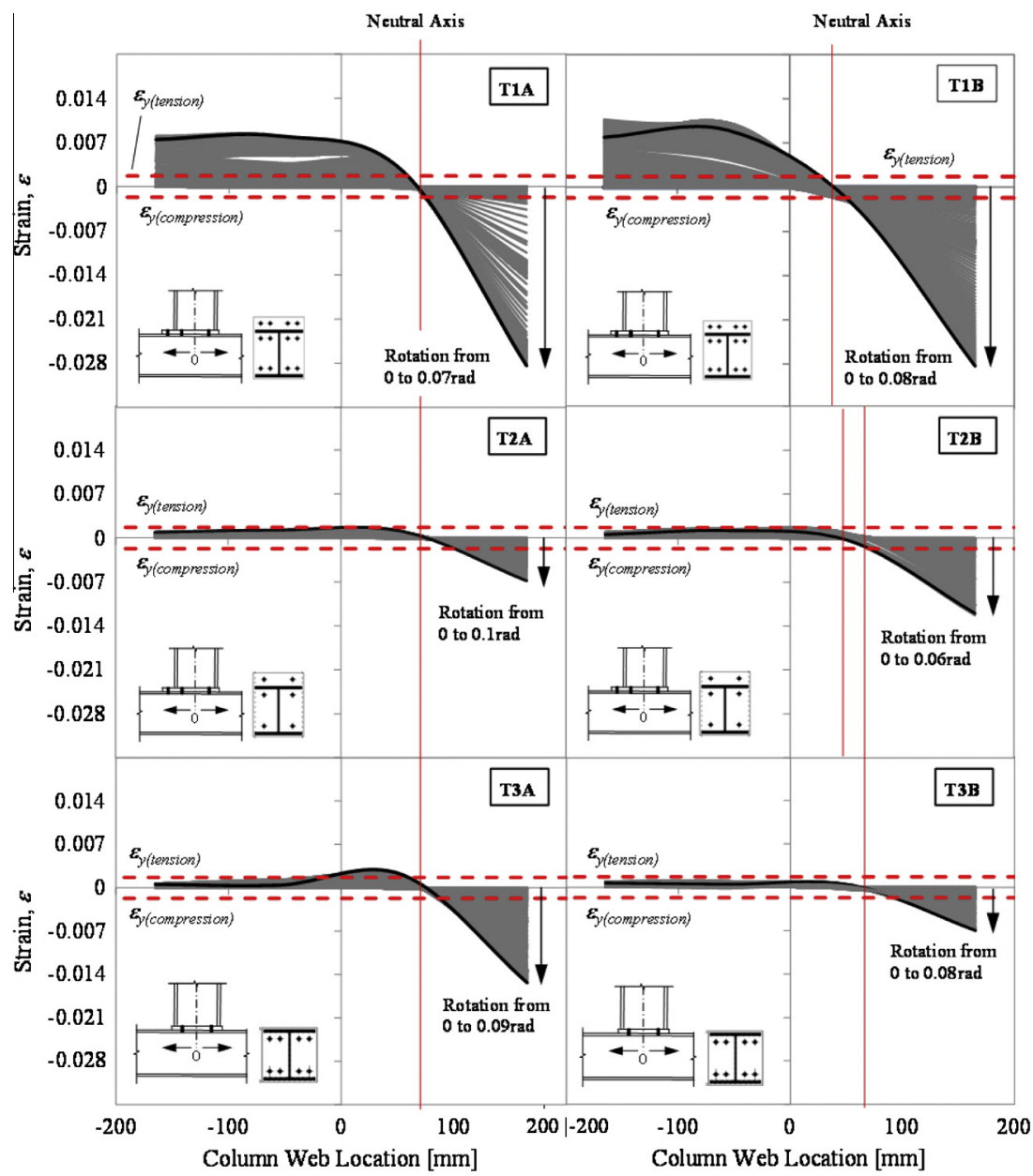

Fig. 9. Column-web strain distribution. 

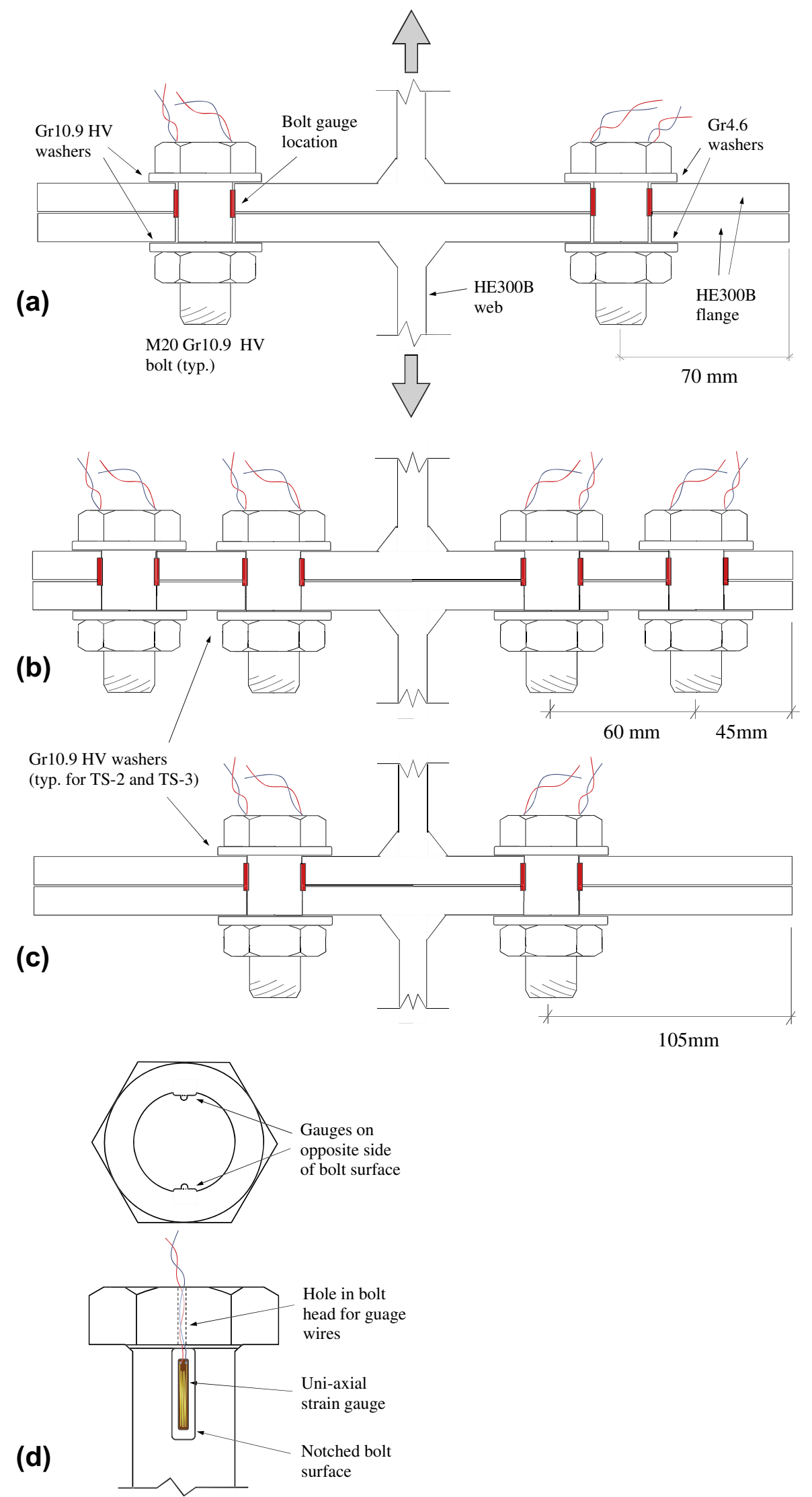

Fig. 10. T-stub configurations for (a) Specimen TS-1, (b) Specimen TS-2, (c) Specimen TS-3 and (d) bolt instrumentation details. 
shows the setup for specimen TS1 including T-stub geometry and bolt locations; Fig. 10(b) and (c) show the setup for specimens TS2 and TS3.

The T-stub connections are fabricated from an HE300B section cut in half at the web centerline, and tested in a universal testing machine with a $1000 \mathrm{kN}$ capacity. Similar to the beam-column experiments, all bolts are pre-tightened to $480 \mathrm{~N}-\mathrm{m}$ as per [16] using a pre-set torque wrench. Each bolt is instrumented with two unidirectional strain gauges positioned $180^{\circ}$ apart and fixed near the bolt surface (see Fig. 10(d)). Attaching gauges on opposite sides of the bolt surface allows for determination of both axial and prying strains during expected deformations of the T-stub.

\subsection{Effect of GR4.6 washers on bolt load and pre-stress}

The use of GR 4.6 washers, rather than GR 10.9 HV washers, has negligible effect on the applied bolt pre-stress. Fig. 11(a) shows the measured axial pre-stress between the bolts having GR 4.6 and GR $10.9 \mathrm{HV}$ washers, with less than $15 \mathrm{MPa}$ difference after the applied torque. This indicates similar friction resistance for both washer strengths, and suggests accurate application of bolt prestress in the beam-column tests.

Measured prying strains between the two bolts were similar, but slightly larger for the GR $10.9 \mathrm{HV}$ bolt. During testing of the T-stub connection, failure of the GR 10.9 HV bolt governed the connection capacity. Fig. 11(b) shows the evolution of bolt surface strains during loading with similar strain distributions observed between the two bolts. Similar pre-stress values and prying strains between the two bolts suggests that the GR 4.6 washers had a negligible effect on the experimental values obtained for the beamcolumn specimens.

\subsection{Bolt participation in configurations having multiple bolts per row}

The outer bolt in the four-bolt-per-row configuration does not contribute to the T-stub resistance until fracture of the inner bolt occurs. Fig. 12 presents the axial and prying strain demands within the bolts of specimens TS2 and TS3, with the inner bolt taking the entire applied load. In Fig. 12, both the axial and prying strains in

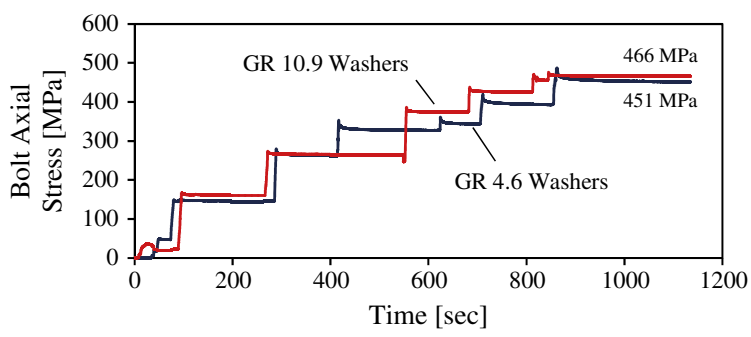

(a)

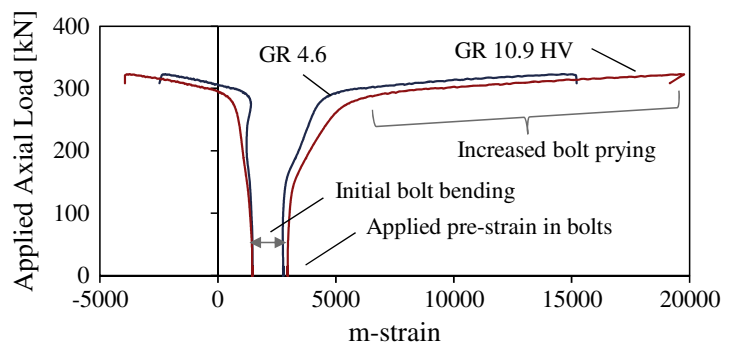

(b)

Fig. 11. (a) Measured bolt axial pre-stress and (b) measured bolt surface strains during loading.

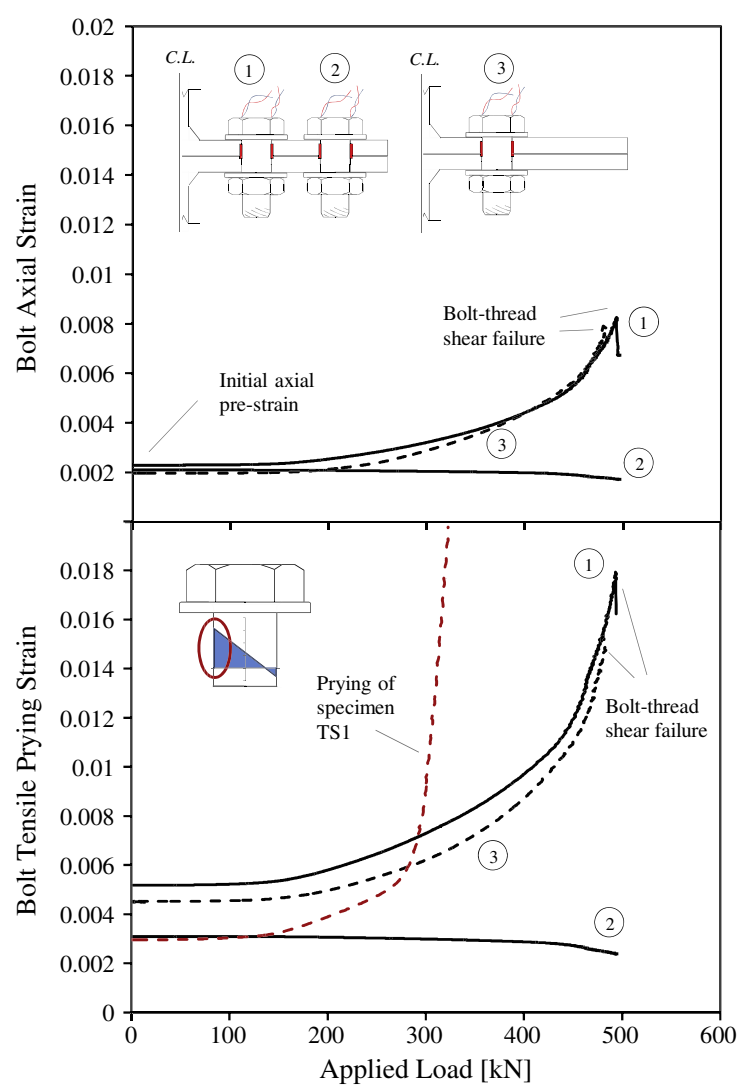

Fig. 12. Bolt axial strain and bolt tensile prying strain for Specimens TS-2 and TS-3.

the outer bolt of specimen TS2 actually decrease during increased loading. Strain demands on the inner bolt are essentially the same between the two configurations. Bolt thread shear was the governing failure mode for both tests, and a similar failure load of near $500 \mathrm{kN}$ was reached.

T-stubs with bolts spaced closer to the web have higher strength. Comparing bolt prying demands and connection strength between all three T-stub tests (see Fig. 12), the critical bolt prying strain for specimen TS1 was reached after $323 \mathrm{kN}$ while the critical prying strain for the bolts of TS2 and TS3 were reached after $514 \mathrm{kN}$ and $483 \mathrm{kN}$ respectively. With similar strength and bolt demands between the TS2 and TS3 T-stub configurations, the increased strength of the four-bolt-per-row beam-column specimens can be directly attributed to bolt spacing relative to the column web.

\section{Numerical modeling}

To investigate parameters not measured experimentally in the beam-column tests, such as continuous connection stresses, each test configuration is analyzed using the finite element method. All finite element models are compared with experimental data. The following sections present the connection modeling techniques, including: element selection, mesh refinement, simulated bolted connection, boundary conditions, and material properties. Results from the simulations and validation will be presented later in the Numerical Results section.

In addition to finite element modeling and for comparison, the behavior of each connection is also predicted using the EC3-1.8 component method, and an extension of the EC3-1.8 component method for post-yield stiffness discussed later. While the EC3-1.8 is based on T-stub tests with only two bolts per row, the method 
is applied to the four-bolt-per-row configurations in this study by neglecting the outer bolts in certain rows (finding two-bolt-perrow T-stubs). Comparison and results between the experiments and component methods are presented later in the Numerical Results section.

\subsection{Finite element modeling methods}

Three-dimensional finite elements, nonlinear multi-directional springs, and various boundary conditions are used to simulate the connection test setup. To allow for detailed determination of stress and strain states throughout the connection assembly, shell elements model the beam web, beam flanges, end-plate, column web, and column flanges. All shell elements are located at the member section centerlines. Pinned boundary conditions at the column ends simulate the column-to-floor attachment in the test, and an applied displacement at the beam tip simulates the horizontal actuator. To prevent local stress concentrations at the pinned column ends and beam tip, rigid nodal constraints distribute the effects throughout the entire member cross-section. Fig. 13(a) shows the model boundary conditions and applied constraints. The welded connection between the beam and end-plate is assumed fixed. The bolted connection between the end-plate and column is simulated using nonlinear multi-directional springs, where the axial and shear resistance of the bolt is provided. To prevent local stress concentrations at the shell-spring junction, the spring force is distributed over a shell area equal to the area of the bolt diameter using rigid nodal constraints (see Fig. 13(b)). All analyses are performed in ABAQUS [18].

Steel material behavior in the beam, column, and end-plate is simulated using a bi-linear material hardening model. Material properties (yield strength, ultimate strength) for the hardening model were taken from the material data provided in Table 2.

Constitutive properties for the nonlinear springs simulating bolt resistance are based on tested strength-deformation values for M20 GR10.9 bolts [11]. A multi-linear material model simulates bolt behavior while in tension, and because the beam endplate is in contact with the column flange while in compression, the

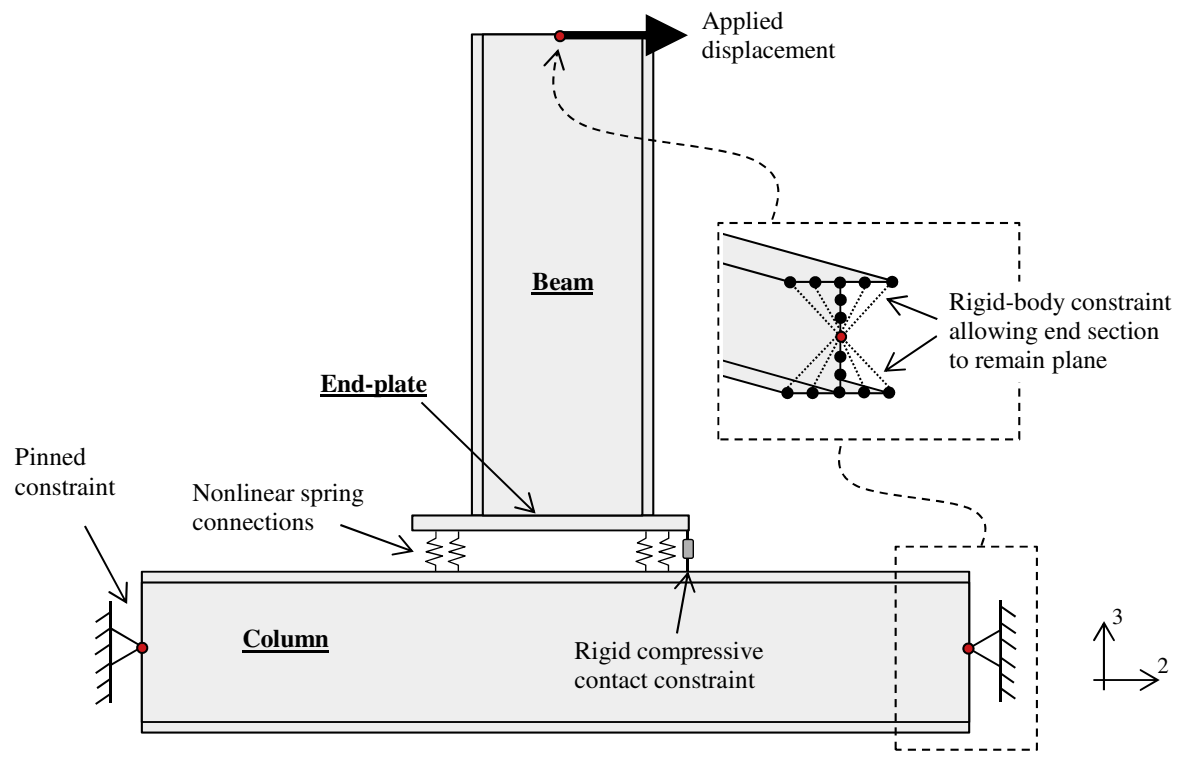

(a)

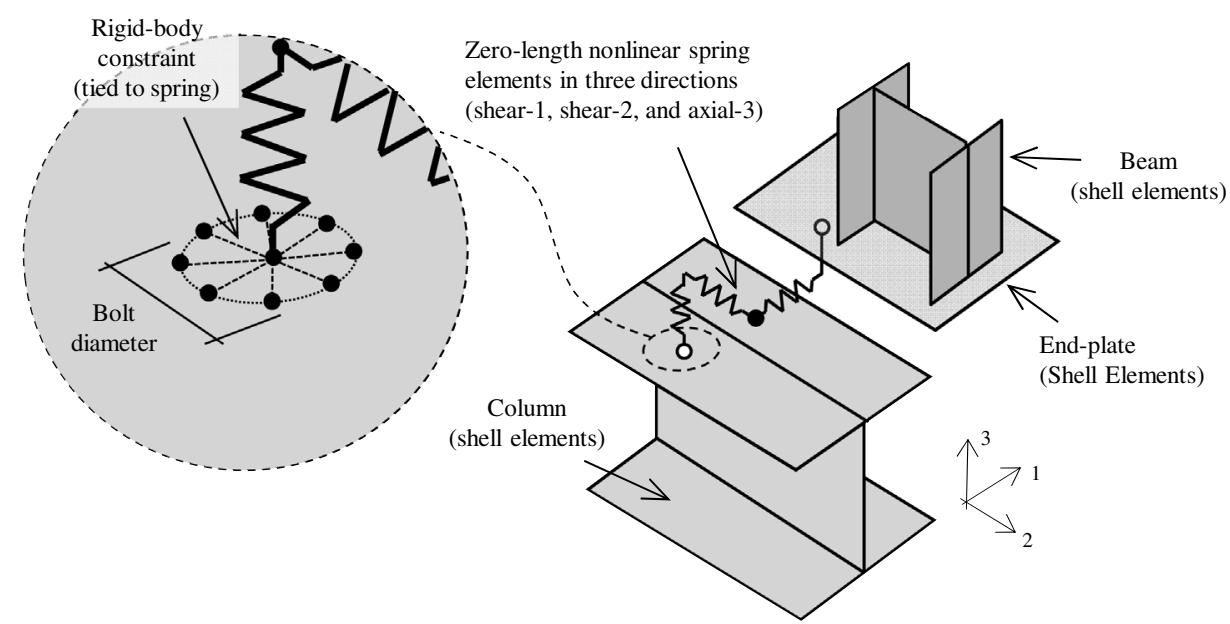

(b)

Fig. 13. (a) Boundary conditions for beam-column connection and (b) modeling techniques for column-to-endplate bolted connection. 


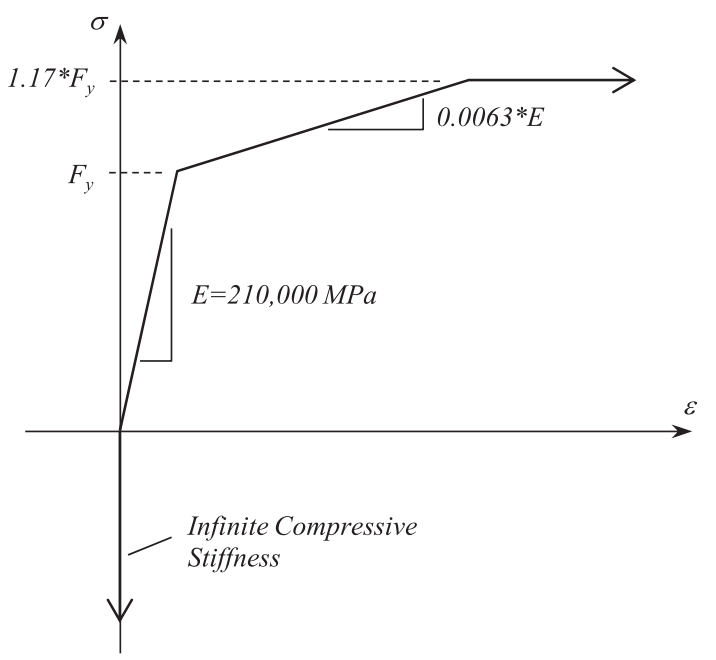

Fig. 14. Bolt material behavior. nonlinear spring is given infinite compressive stiffness. Fig. 14 shows the multi-linear bolt behavior in terms of the bolt yield stress ( $F_{y}$ taken in this study as $990 \mathrm{MPa}$ ).

\subsection{Component methods}

The EC3-1.8 component method can be used to predict the onset of material yielding. This method served as a basis to a numerical analysis tool called NASCON $[19,20]$. While NASCON does the computations according to the EC3-1.8 method, it also contains an extension which allows for prediction after yielding and thus post-yield stiffness and ductility of the joints.

The resistance of each connection configuration is determined by the EC3-1.8 component method, as well as a modified version of the EC3-1.8 method (herein called NASCON method). The EC31.8 component method considers a bilinear, elastic-plastic, connection response while the adapted NASCON method accounts for post-yield connection stiffness and potential nonlinear connection behavior. For the NASCON method, computations are made using the component material data provided in Table 2 and

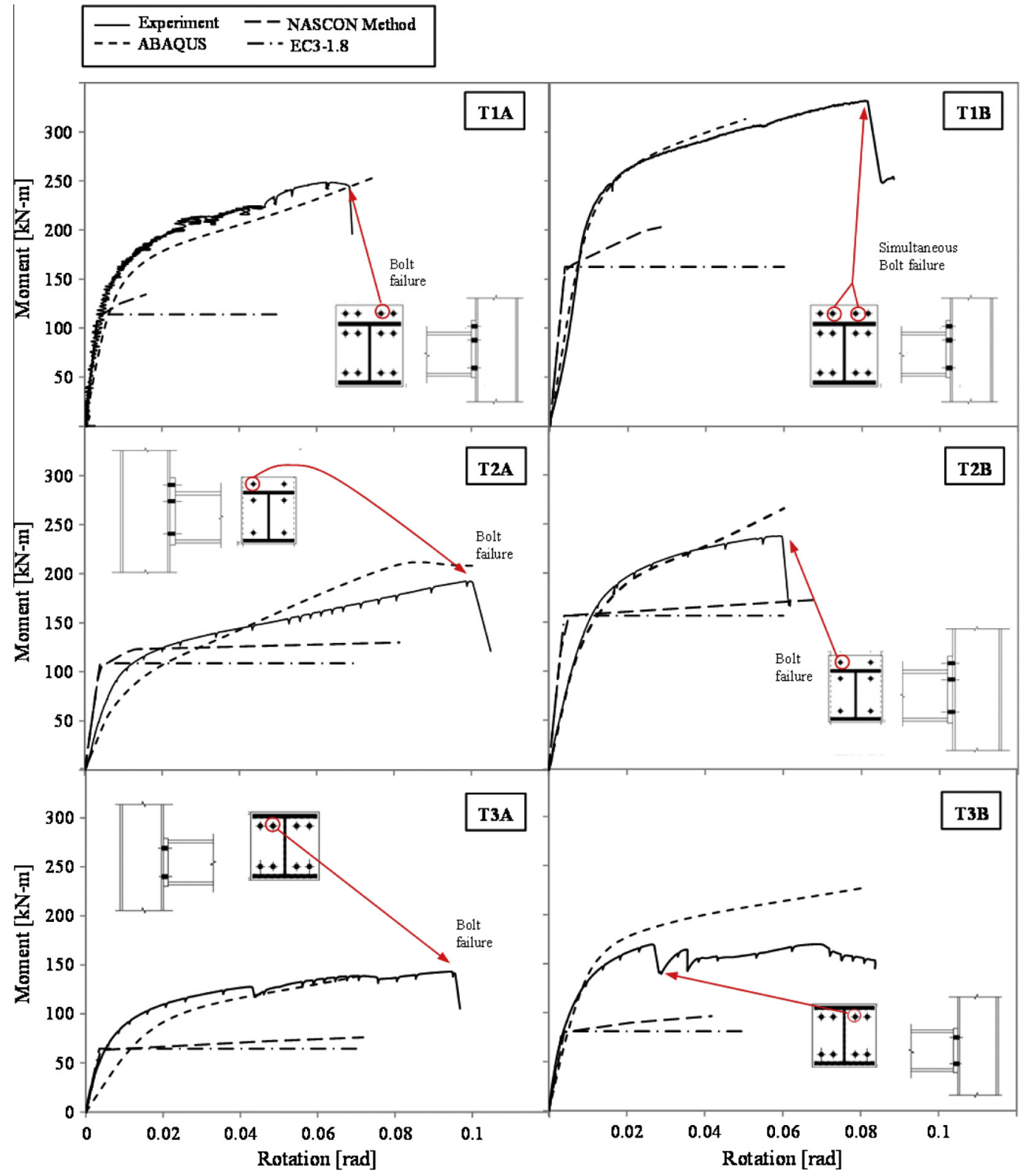

Fig. 15. Comparison between experiment, finite element simulation, and component methods. 
nominal member dimensions provided in [17]. Individual component post-yield behavior in NASCON is determined by a genetic algorithm fit to existing beam-column test data (considering only two-bolt-per-row configurations), as provided in de Lima et al. [21]. For the EC3-1.8 component method, computations are made using EC3 design material values as well as resistance factors, i.e. the values computed corresponding to application of the code in engineering offices.

For configurations having multiple bolts per row, additional connection resistance values are analytically determined using Tstub equations for four bolts per row developed by Demonceau et al. [14]. In [14], the formulas are in full agreement with the Eurocode component method approach and result in updated resistance values for failure modes involving combined flange yielding and bolt failure (the predominant failure mode observed in the beam-column tests).

\section{Numerical results}

\subsection{Comparison between FEA, experimental response, and component methods}

The finite element simulations are able to capture the global inelastic moment-rotation behavior observed in the experimental tests, while the NASCON component method significantly underpredicts the observed strength and post-elastic resistance. Fig. 15 shows the moment-rotation comparison between the finite element analysis, experimental measurements, NASCON method, and EC3-1.8 component method. Table 4 presents the rotational stiffness, peak rotation, comparative strength values at $0.02 \mathrm{rad}$, and the different failure limits for the experiments, analyses, the NASCON method, and the EC3-1.8 component method. Note that, as expected, the EC3-1.8 component method values are systematically lower than the NASCON values.

The value of $0.02 \mathrm{rad}$ was chosen due to the early failure of specimen T3B. Note that the classical failure limit predicted by the finite element and NASCON simulations is based on the location of initial yielding. At a rotation of $0.02 \mathrm{rad}$, all finite element simulations are within $12 \%$ on average of experimental observation. For specimen T3B which experienced early bolt thread shear, the finite element values are above the experimental ones. In general, the finite element simulations fit reasonably with the experiments.

The NASCON method usually leads to lower strength values than the finite element simulations, except for specimen T2A. The EC3-1.8 component method values are always on the safe side by at least $11 \%$ (note that it includes resistance factors). For test specimens T1A, T2A, and T3A having smaller column cross-sections, the initial connection stiffness is slightly under-predicted by the finite element simulations (see Fig. 15, and the values presented in Table 4); the stiffness predicted both by the NASCON and the EC3-1.8 component methods are close to experimental results.

Connection resistance using the four bolts per row T-stub equations by Demonceau et al. [14] is close to experimental observation. Using the equations presented in [14] and from a governing T-stub failure mode involving combined flange yielding and bolt failure, connection resistance for specimen T1B is calculated as $260.8 \mathrm{kN}$. From Table 4, experimental testing indicates a resistance of specimen T1B (at $0.02 \mathrm{rad}$ ) equal to $262.4 \mathrm{kN}$. While the ultimate resistance for specimen $\mathrm{T} 1 \mathrm{~B}$ eventually reached $331 \mathrm{kN}$ at $0.08 \mathrm{rad}$ after material strain-hardening, significant loss in stiffness was observed around 0.02 rad (see Fig. 15).

In addition to the global connection behavior, eight strain gauges located on both sides of the column webs allow for

Table 4

Connection strength, stiffness, and rotation values for experimental testing, finite element analysis, and component methods.

\begin{tabular}{|c|c|c|c|c|c|c|}
\hline Specimen & $\begin{array}{l}\text { No. of } \\
\text { bolts }\end{array}$ & $\begin{array}{l}\text { Strength at } 0.02 \text { rad } \\
(\mathrm{kN} \mathrm{m})\end{array}$ & $\begin{array}{l}\text { Initial rotational stiffness } \\
(\mathrm{kN} \mathrm{m})\end{array}$ & $\begin{array}{l}\text { Peak rotation } \\
\text { (rad) }\end{array}$ & $\begin{array}{l}\text { Remark, classic failure limit state (initial } \\
\text { yielding) }\end{array}$ & $\begin{array}{l}\text { Ultimate failure limit } \\
\text { state }\end{array}$ \\
\hline \multicolumn{7}{|c|}{ Experimental testing } \\
\hline T1A & 12 & 193.5 & 26,341 & 0.069 & Column flange bending & Tensile bolt failure \\
\hline $\mathrm{T} 2 \mathrm{~A}$ & 6 & 122.1 & 12,346 & 0.105 & Column flange bending & Tensile bolt failure \\
\hline T3A & 8 & 109.8 & 14,268 & 0.097 & Column flange bending & Tensile bolt failure \\
\hline T1B & 12 & 262.4 & 22313 & 0.081 & Column flange bending & Tensile bolt failure \\
\hline T2B & 6 & 196.4 & 17,577 & 0.062 & Column flange bending & Tensile bolt failure \\
\hline Т3В & 8 & 161.3 & 27,277 & $0.027^{\mathrm{a}}$ & Column flange bending & Bolt thread shear \\
\hline \multicolumn{7}{|c|}{ Finite element analysis } \\
\hline $\mathrm{T} 1 \mathrm{~A}$ & 12 & 179.3 & 19,501 & $-{ }^{\mathrm{b}}$ & Column flange bending & $-{ }^{\mathrm{b}}$ \\
\hline $\mathrm{T} 2 \mathrm{~A}$ & 6 & 107.3 & 9140 & - & Column flange bending & - \\
\hline T3A & 8 & 96.9 & 5816 & - & Column flange bending & - \\
\hline T1B & 12 & 261.9 & 23,802 & - & Column flange bending & - \\
\hline T2B & 6 & 190.2 & 17,676 & - & Column flange bending & - \\
\hline T3B & 8 & 177.0 & 16,367 & - & Column flange bending & - \\
\hline \multicolumn{7}{|c|}{ NASCON method } \\
\hline $\mathrm{T} 1 \mathrm{~A}$ & 12 & $133.6^{c}$ & 33,625 & $-{ }^{\mathrm{b}}$ & Column web compression & $-{ }^{\mathrm{b}}$ \\
\hline $\mathrm{T} 2 \mathrm{~A}$ & 6 & 124.0 & 27824 & - & Column flange bending & - \\
\hline T3A & 8 & 66.6 & 16,503 & - & Column flange bending & - \\
\hline T1B & 12 & 191.8 & 42,140 & - & Column flange bending & - \\
\hline T2B & 6 & 160.8 & 39,685 & - & Column flange bending & - \\
\hline Т3В & 8 & 89.4 & 20,290 & - & Column flange bending & - \\
\hline \multicolumn{7}{|c|}{ EC3 component method } \\
\hline T1A & 12 & 114.0 & 33,008 & $-{ }^{\mathrm{b}}$ & Classified as semi-rigid & $-{ }^{\mathrm{b}}$ \\
\hline $\mathrm{T} 2 \mathrm{~A}$ & 6 & 108.8 & 27,420 & - & Classified as semi-rigid & - \\
\hline T3A & 8 & 64.7 & 18,576 & - & Classified as semi-rigid & - \\
\hline T1B & 12 & 162.6 & 41,835 & - & Classified as semi-rigid & - \\
\hline T2B & 6 & 156.5 & 38,967 & - & Classified as semi-rigid & - \\
\hline Т3B & 8 & 81.1 & 23,824 & - & Classified as semi-rigid & - \\
\hline
\end{tabular}

\footnotetext{
a Reduction to $80 \%$ of ultimate capacity after $0.027 \mathrm{rad}$, specimen regained strength and achieved $0.084 \mathrm{rad}$.

b Not applicable.

c Failure predicted at 0.016 rad.
} 
validation of the finite element techniques through comparison of localized member strains. Local member strains cannot be determined using the EC3-1.8 or NASCON component methods. Strain values from the finite element models were taken at the same geometric location as the applied strain gauges in the experimental tests. Fig. 16 shows the distribution of column web strains for each test (values taken at the peak connection rotation) and the corresponding prediction from the finite element simulation. From Fig. 16, the connection simulations adequately capture the local member behavior, with configuration T3A being within $8 \%$ of the experimental readings and the largest discrepancy being $43 \%$ in configuration T1A.

With confidence in the global and local model behavior, the finite element simulations can be used to investigate parameters not easily obtained during experimental testing (localized bolt demands, connection stress distributions around bolt holes, etc.).

\subsection{Influence of bolt grouping on bolt demands}

With bolt fracture ultimately limiting the rotation capacity of each test specimen, understanding the state of stress in each bolt can help identify potential performance issues between different bolt configurations. Fig. 17(a) through Fig. 17(c) show the individual column-flange bolt bearing stresses (obtained from finite element simulations) for configurations T1B, T2B, and T3B. While the bolt element was not explicitly modeled, equilibrium between the bolt and column flange allows insight into bolt stress distributions. As expected from the observed bolt fractures during testing, the closer the bolt is to the column web, the higher the stress in the bolt. In Fig. 17(a) and (b), having four bolts per row in the connection tensile region, stress concentrations occur in the inner bolts (those closest to the column web) on the inner bolt section, and reduce within the bolt section moving away from the column web (432 MPa to $373 \mathrm{MPa}$ in bolt 3 of configuration T1B, and $433 \mathrm{MPa}$ to $375 \mathrm{MPa}$ in bolt 3 of configuration T3B, see Fig. 17(a) and (c)). These bolt stress concentrations and stress distributions are due to prying caused by deformations between the column web and beam endplate. The stress values (432 MPa, $373 \mathrm{MPa}$, etc.) are limited by the material inelastic strength gain of the column flange. Stress distributions in configuration T2B, having only one bolt on either side of the column web (two bolts per row), are more uniformly distributed across the bolt section similar to the exterior bolts in configurations T1B and T3B (compare Fig. 17(b) with Fig. 17(a) and (c)).

\section{Summary and conclusions}

In this study, six beam-column connections having thick endplates and different bolt configurations, including configurations with multiple bolts per row, were tested to failure under static pushover loading. All configurations were fabricated without column web stiffeners outside the bolted connection. The six connections represented two strength scenarios: (1) a weak-column strong-beam scenario (with HE300A and HE300B sections for the column and beam respectively), and (2) an equal-beam equal-column scenario (with HE300B sections for both the column and beam). Additional T-stub tests and analytical simulations validated from the experimental tests provided insight into local connection

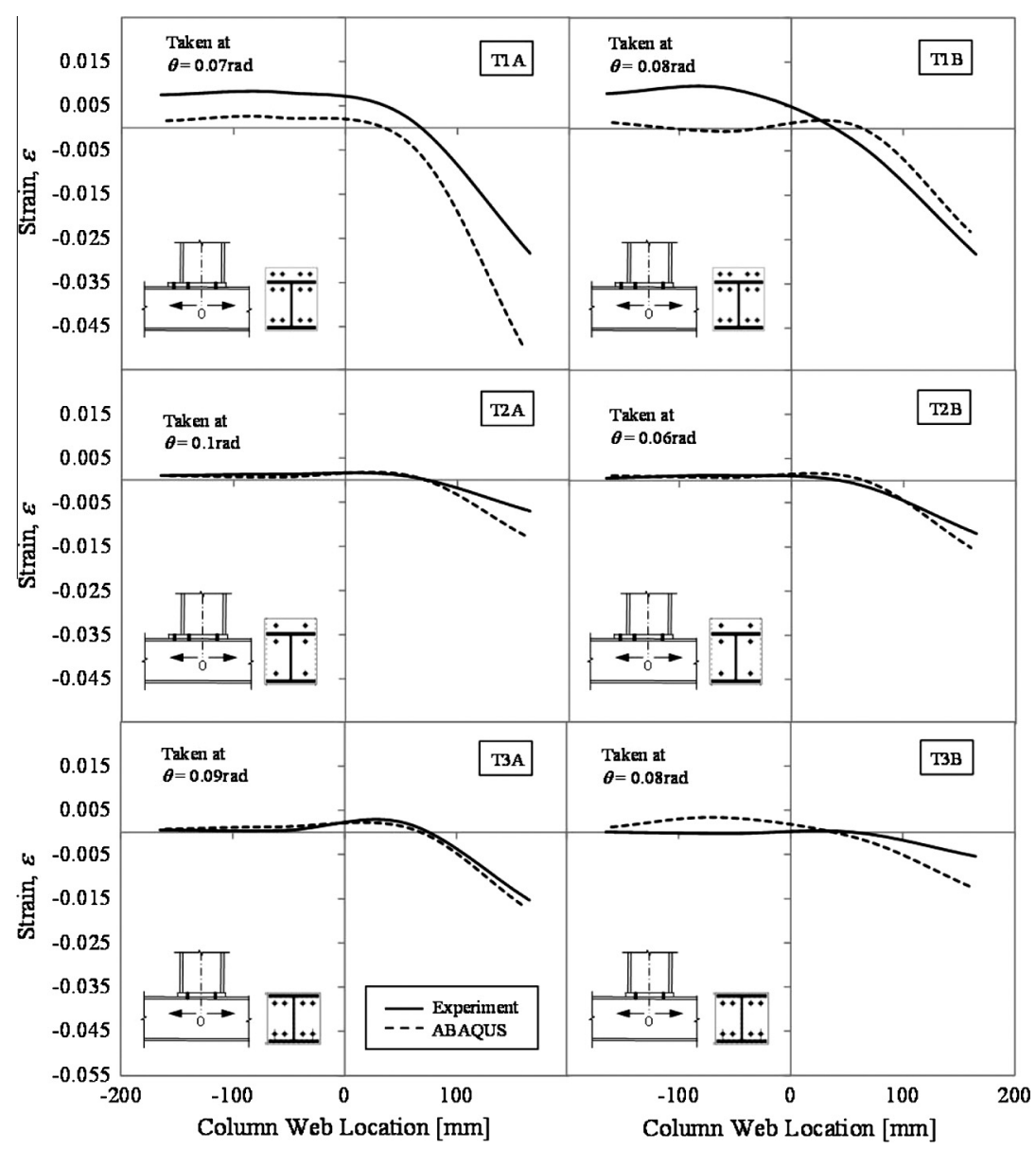

Fig. 16. Comparison between strains from experiments and finite element simulations. 

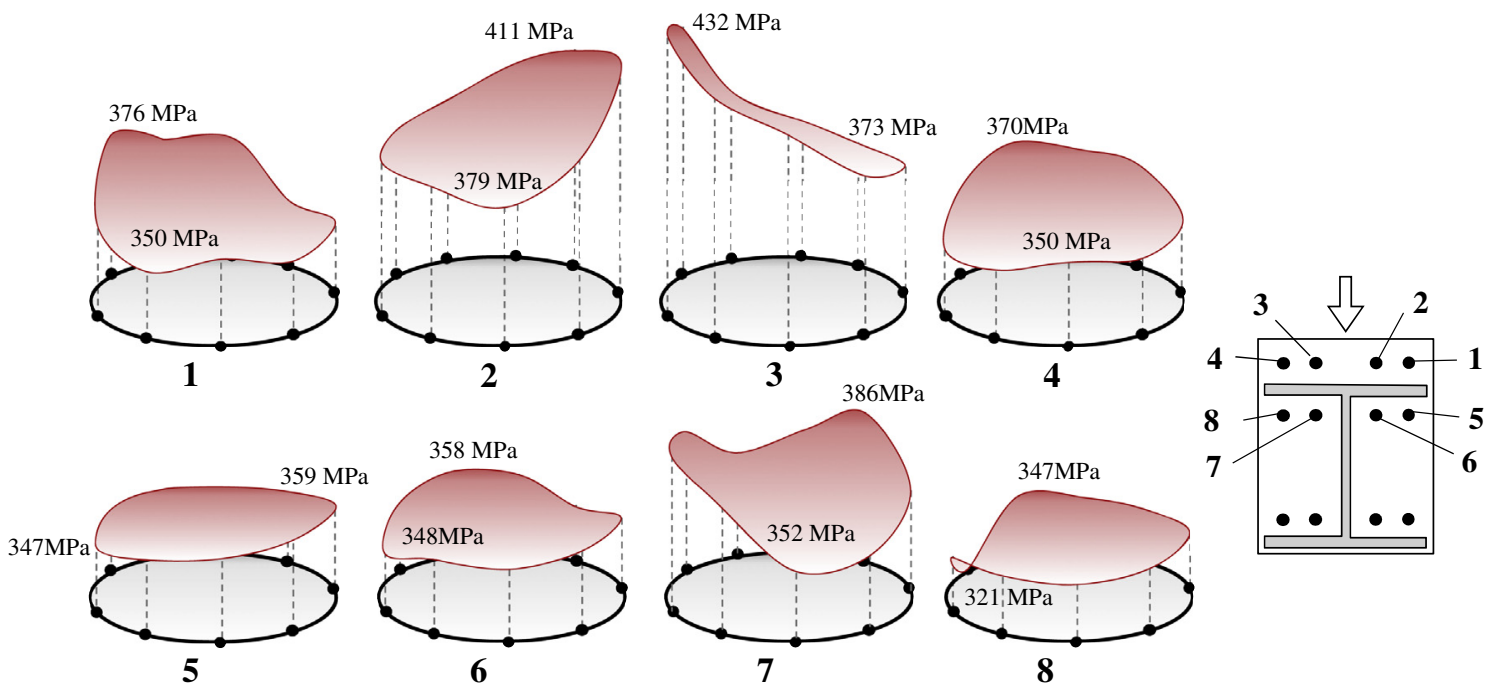

(a)
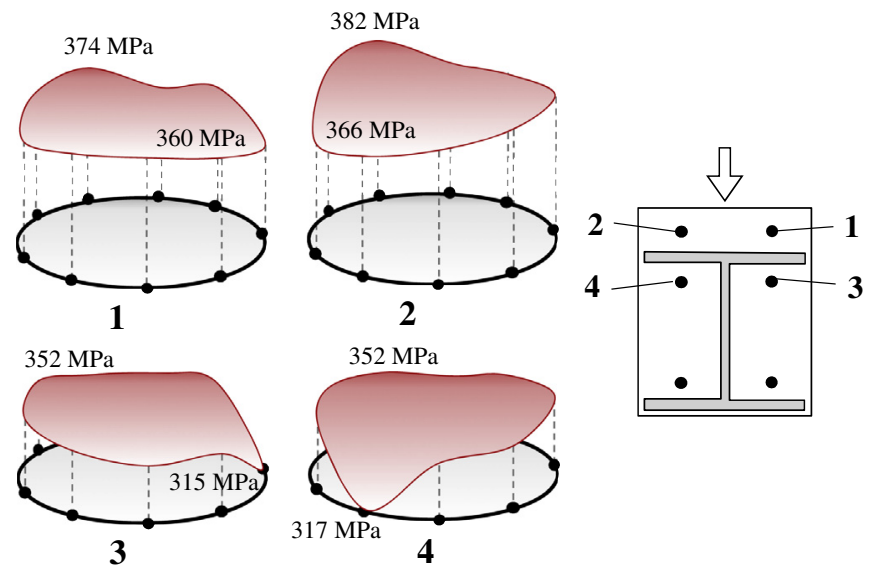

(b)
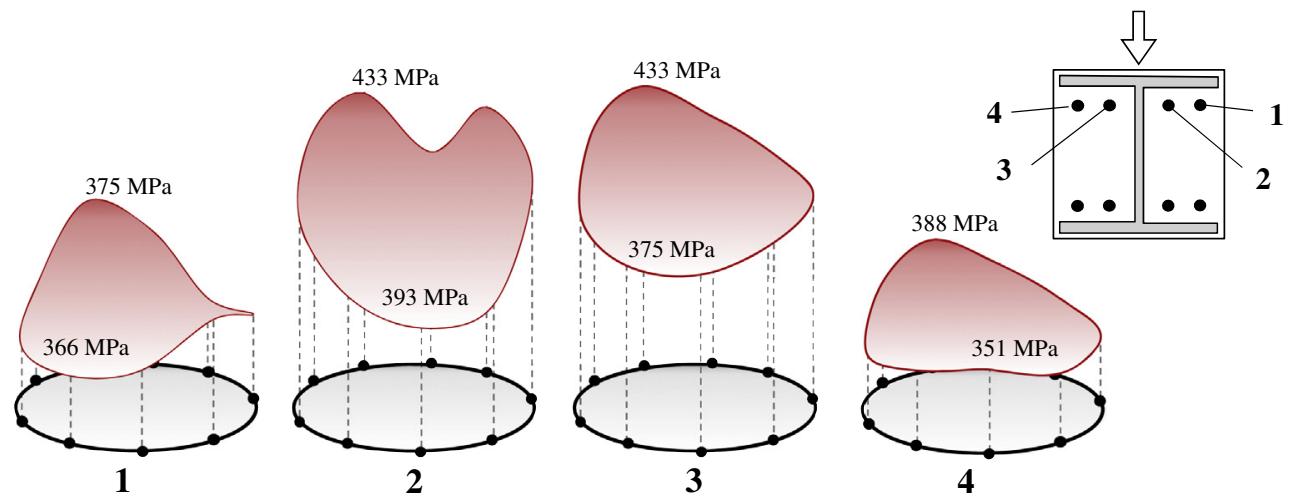

(c)

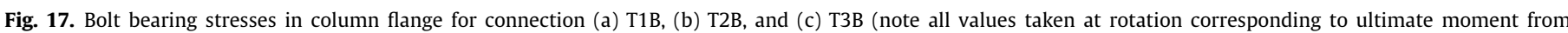
experimental testing).

behavior. Global connection behavior from the experimental tests and local connection behavior from analytical simulations were compared with current code methods.

The following conclusions are based on the experimental testing and analytical simulation of the six beam-column connections:
(1) Deformations in the column section govern the failure of equal-column equal-beam or weak-column strong-beam connections when thick endplates are present (endplate greater than or equal to 1.5 times the flange thickness, and when column web stiffeners are not provided in the column). As bolt locations move toward the column web 
centerline, bolt prying forces increase at lower connection rotations due to column flange distortions from the higher transverse stiffness of the column web. This has implications for configurations having multiple bolts per row, as limited space often requires positioning of bolts near the column web.

(2) Configurations having multiple bolts per row increase connection moment capacity for both weak-column strongbeam and equal-column-beam scenarios, solely due to closer inner bolt spacing to the column web. T-stub testing with instrumented bolts indicates that outer bolts in multiplebolt-per-row configurations contribute very little to the connection resistance when column web stiffeners are not included. Closer inner bolt spacing (relative to the column web) decreases rotation capacity in weak-column strongbeam scenarios due to increased bolt prying forces and earlier bolt failure from column flange distortions (compare experimental result for specimen T1A and T2A in Fig. 8). The rotation capacity for all tests was still greater than $0.027 \mathrm{rad}$.

(3) The use of GR4.6 washers rather than GR10.9 washers has negligible effect on bolt pre-stress values and bolt prying demands.

(4) The two-dimensional connection representation with EC31.8 component method consistently under-predicted connection strength, but correctly identified the flange bending initial limit-state. The mean connection strength predicted by the EC3-1.8 component method was $27 \%$ lower than experimental result (mean connection over-strength of 1.37 at 0.02 rad of rotation). T-stub resistance equations by Demonceau et al. [14], considering four bolts per row, reasonably predicted the capacity of specimen T1B.

(5) Finite element simulation with shell elements and nonlinear springs is reasonably accurate for determining post-elastic global and local response of bolted beam-column connections having thick endplates and multiple bolts per row. The EC3-1.8 method provides a conservative estimation of connection strength for connections having thick endplates and multiple bolts per row.

\section{Acknowledgements}

The authors acknowledge the financial support provided by the Swiss Institute for Steel Construction (SZS) and by Sottas SA, who fabricated the test specimens. Laboratory staff instrumental in the completion of this work include: Sylvain Demierre, Gerald
Rouge, and Frederique Dubugnon. Many thanks also go to Mr. Paul Maurice for his assistance with the test specimen preparation, and to Professor Christoph Gemperle for his guidance as a member of the new SZS Table C-9 working group. Feedback from reviewers significantly improved the paper.

\section{References}

[1] Jones SW, Kirby PA, Nethercort DA. The analysis of frames with semi-rigid connections - a state-of-the-art report. J Constr Steel Res 1983;3(2):2-13.

[2] Eurocode 3. Design of steel structures part 1-8: design of joints. European Standard EN 1993-1-8. European committee for standardization, Brussels, Belgium; 1993.

[3] Zoetenmeijer P. Summary of the research on bolted beam-to-column connections (period 1978-1983). Report No. 6-85-M. Steven Laboratory, Delft; 1983.

[4] Zoetenmeijer P. Proposal for standarisation of extended end plate connection based on test results. Report No. 6-83-23. Steven Laboratory, Delft; 1983.

[5] Aggarwal AK, Coates RC. Moment-rotation characteristics of bolted beamcolumn connections. J Constr Steel Res 1986;6:303-18.

[6] Aggarwal AK, Coates RC. Strength criteria for bolted beam-column connections. J Constr Steel Res 1987;7:213-27.

[7] Davison JB, Kirby PA, Nethercot DA. Rotational stiffness characteristics of steel beam-to-column connections. J Constr Steel Res 1987;8:17-54.

[8] Popov EP, Takhirov SM. Bolted large seismic steel beam-to-column connections. Part 1: Experimental study. Eng Struct 2002;24:1523-34.

[9] Kukreti AR, Zhou F-F. Eight-bolt endplate connection and its influence on frame behavior. Eng Struct 2006;28:1483-93.

[10] Bahaari MR, Sherbourne AN. Behavior of eight-bolt large capacity endplate connections. Comput Struct 2000;77:315-25.

[11] Shi Y, Shi G, Want Y. Experimental and theoretical analysis of the momentrotation behavior of stiffened extended end-plate connections. J Constr Steel Res 2007;63:1279-93.

[12] Shi G, Shi Y, Wang Y, Bradford MA. Numerical simulation of steel pretensioned bolted end-plate connections of different types and details. Eng Struct 2008;30:2677-86.

[13] Abidelah A, Bouchair A, Kerdal DE. Experimental and analytical behavior of bolted end-plate connections with or withour stiffeners. J Constr Steel Res 2012;76:13-27.

[14] Demonceau J-F, Jaspart J-P, Weynand K, Oerder R, Muller C. Connections with four bolts per horizontal row. In: Proc Eurosteel, Budapest, Hungary; 2011.

[15] Kozlowski A, Pisarek Z. Resistance and stiffness of T-stub with four bolts. Arch Civil Eng 2008;54(1):167-91.

[16] SZS. Tables pour la construction metallique, C5/97. Centre suisse de la construction metallique, Zurich, Switzerland; 1997.

[17] SZS. Tables de dimensionnement C4/06. Centre suisse de la construction metallique, Zurich, Switzerland; 2006.

[18] HKS. ABAQUS standard users manual, Version 6.4. Hibbitt, Karlsson, and Sorensen Inc.; 2006.

[19] Gervasio H, Simoes da Silva L, Borges L. Reliability assessment of the post-limit stiffness and ductility of steel joints. J Constr Steel Res 2004;60:635-48. issues 3-5.

[20] Borges L. Evaluation of the rotation capacity of steel joints. MSc Dissertation, University of Coimbra, Coimbra, Portugal; 2003.

[21] de Lima LRO, da S.Velasco PCG, da Silva JGS, Borges LAC, da Silva LAPS. Postlimit stiffness prediction of semi-rigid joints using genetic algorithms. Latin Amer J Solids Struct 2005;2:305-20. 